\title{
Development and Preliminary Validation of the Older Adult Service Usage Assessment
}

\author{
Nancy J. Karlin \\ School of Psychological Sciences, University of Northern Colorado, Greeley, CO, USA \\ Email: nancy.karlin@unco.edu
}

How to cite this paper: Karlin, N.J. (2017) Development and Preliminary Validation of the Older Adult Service Usage Assessment. Advances in Aging Research, 6, 61-72.

https://doi.org/10.4236/aar.2017.64007

Received: June 1, 2017

Accepted: July 17, 2017

Published: July 20, 2017

Copyright $\odot 2017$ by author and Scientific Research Publishing Inc. This work is licensed under the Creative Commons Attribution International License (CC BY 4.0).

http://creativecommons.org/licenses/by/4.0/

\section{Open Access}

\begin{abstract}
This study provides information on the development and factor scaling, validity, and reliability of a newly developed community service utilization measure (Older Adult Service Usage Assessment-OASUA). Analyzes indicate the OASUA can be used to assess current perceived community service use and satisfaction, as well as providing an indication for future service use and potential service needs with older persons. Additional data collection sites should be identified and a broader sample obtained so as to confirm the psychometric properties of the instrument in conjunction with further development of the OASUA.
\end{abstract}

\section{Keywords}

Older Adult, Home and Community-Based Services, Rural Aging

\section{Introduction}

Information about the use and perceived future availability of Home and Community-Base Services (HCBS) for the rural older adult is limited [1]. HCBS is a federally funded program that is designed to meet the needs of people who prefer to obtain long-term care services and supports in their home or community, rather than in an institutional setting [2]. Rural older adults continue to experience less access (e.g., limited transportation, longer travel distances, etc.) to community-based services [3] [4] [5]; are socially isolated [6], and are less aware of potential services leading to lower overall service use [7]. It is this lack of access, social isolation, and limited service awareness and subsequent use that leaves rural older adults without adequate care and services that might promote overall health and a higher quality of life.

Recognizing needs of rural older adults are constrained by a lack of knowledge on factors impacting rural aging in place [8], the overall goal of this project was 
to develop an instrument for gathering information about HCBS. This needs assessment, which identifies older adults' HCBS use and satisfaction, and possible future service use along with perceived needs, was developed by the current author and was used to survey older adults in rural western Nebraska and throughout the Eastern Plains of Colorado. These regions were selected for their proximity to one another, similar distance to urban services, and comparable population density. As a result, data from 176 rural older adult participants were used to measure the Older Adult Service Usage Assessment's (OASUA) reliability, content and construct validity (convergent and discriminant), and factor structure.

\subsection{HCBS Measurement Need}

The study builds upon current Affordable Care Act's Medicare and Medicaid innovative initiatives (March 2016) that call for population-specific, effective long-term home-based services [9]. What is known about HCBS use comes primarily from institutional reports rather than individual measurement [10]. If there is individual measurement, data rely on caregiver reports to assess services and needs of older rural people [11], does not focus on older adults [12], or measures only home care satisfaction [13].

Using the need component of the Social Behavior Model [14], the current study focused on the perceived service needs of older persons in rural communities for the development of the OASUA. An earlier version of this model [15], which was originally not adapted for older people, was tested by Sonnega et al. (2016). In this first national HCBS service use study, the researchers found many common HCBS services were not available in the 19 community-services identified. The HCBS user in this national study included individuals who were female, low SES, black or Hispanic minority status, on Medicaid, over the age of 75, and not employed. Creation of an instrument that measures a more comprehensive number of individual community-based services used by rural older adults was necessary.

\subsection{Older Adult Service Usage Assessment (OASUA)}

The OASUA was developed to measure current and future perceived need and expressed use of HCBS programs along with service satisfaction. The OASUA generates information based on dimensional HCBS use. Survey items were derived from Area Agency on Aging (AAA) fliers of services available within these rural areas. Operating from a foundation of perceived and expressed needs, the first 43 service items assess current or recent service use on a 6-point scale (i.e., 0 = no use, 1 = single use, $2=$ multiple uses but not weekly, $3=$ weekly, $4=$ twice a week, $5=$ more than twice week) along with service satisfaction (i.e., $0=$ not satisfied, 1 = limited satisfaction, $2=$ some satisfaction, $3=$ moderately satisfied, 4 = very satisfied, $5=$ extremely satisfied). The second 43 items measure perceived future service utilization (i.e., no use, single, use, multiple uses but not weekly, weekly, twice a week, more than twice week) and potential future needs (i.e., not 
needed, limited need, some need, moderate need, very needed, extremely needed). This scoring format allows for a possible indication on awareness of service availability and frequency of specific service use.

Scoring of the OASUA. The easily scored structure of the OASUA allows for individual or group identification on the total number of services used to date, frequency of specific services, satisfaction with prior services, total number of services predicted for future use, potential frequency of future identified services, and the perceived need of specific services required for the future. Access to services is indicated with completion of the OASUA along with the potential for additional prompts to be added. Self-administration time for the OASUA is approximately 10-15 minutes. Individuals with lower literacy rates may require additional time or assistance. Anyone with literacy below the $6^{\text {th }}$ grade or who use English as a second language should be provided assistance. The benefits of using the OASUA include ease of use, speed of completion, ease of scoring, and applicability to a wide range of older adults. The OASUA is a measure that focuses on service use and is a valid and reliable instrument. The OASUA generates information based on dimensional HCBS use (e.g., current expressed service use and satisfaction, and future possible use and perceived needs). It appears to also be reliable, demonstrates content validity (service use), while also measuring convergent validity and discriminant validity.

As a result of the service rural service gap for use and perceived availability of services, the intent of the study was to (a) develop an appropriate assessment of service use for older adults; and (b) evaluate reliability, validity, and factor loadings for the OASUA. Development of such an instrument has the potential for promoting healthy community-based living through measurement of community services used by older adults either through a single point of measure or by identifying service use changes over time.

\section{Methodology}

\subsection{Procedures}

Power analysis indicated a minimum of 88 participants from each of the two regions was required to complete a comparison at an alpha of 0.05 . A total of 176 face-to-face interviews were conducted with comparison groups of older adults residing in rural eastern Colorado and western Nebraska. The Older Americans Act of 1965 defined an older adult as any individual over the age of 60. This Act provides guidelines for service eligibility for older adults [16]. Through interview or guided self-completion, which allows for definitions to be provided and probes to be used, the OASUA was administered. Participants were obtained via convenience sampling, which has been found to be an effective manner to obtain entrance into difficult to obtain communities such as older adults aging in place. For the current study, participants were excluded if they did not meet the age or region criteria. If required, cognitive impairment would have been assessed using the Mini Mental State Examination with a cut-off score of 20/30 or below needed for participation. No such assessment was mandated. Information was 
provided on specific services of interest with the completion of each survey.

\subsection{Western Nebraska and Eastern Plains of Colorado Participants}

Participants were selected from the western portion of Nebraska and from the Eastern Plains of Colorado because minimal research on older adult service use has been completed for these regions. Limited prior research from rural $\mathrm{Ne}$ braska and Colorado suggests the importance on the development of a needs assessment and the identification of older adult HCBS perceptions. The current study is significant in that it occurred in two states with similar rural regions that are experiencing modest success for HCBS and with an older population (65+) growing faster than state growth rates in the same demographic [17] [18]. All counties that are part of the current study have a health professional shortage, are eligible for Center for Medicaid Services-Rural Health Clinics Program, and for Federal Office of Rural Health Policy grant programs [19]. Additionally, no data for Colorado are included in the Medicaid Analytical Extract (MAX) for either the 2008 or 2011 extract and each state's HCBS program differs in its eligibility criteria, funding amounts, and possible service use [1]. The development of this instrument, which specifically measures the frequency of current service use and satisfaction, and future use and perceived service needs, was created for initial use in these two areas.

Participants included 117 females (66.5\%) and 59 males (33.5\%) who were primarily Caucasian $(n=169,96.0 \%)$ residing in rural western Nebraska or the Eastern Plains of Colorado. Participant average age was 75.77 years $(S D=7.57$, range $=60-96$ years) with $22.2 \%$ having a bachelor's degree or higher level of education. Those who completed the measure were generally married at the time of interview (56.8\%) as compared to those who were widowed (26.7\%), divorced (14.2\%), or never married (2.3\%). The primary source of income was Social Security (84.7\%), 35.8\% indicated having only one source of income, $30.7 \%$ reported two sources, $24.4 \%$ stated three sources, $6.3 \%$ four sources, and $2.8 \%$ reported five sources (e.g., social security, savings, investments, pension, and land). No differences between the comparison groups were indicated for age (Nebraska, $M=76.2$; Colorado, $M=75.2$ ), $F(1,174)=0.838, \eta=.374, p=0.36$. Between group differences were identified for gender, $\chi^{2}(1, N=176)=4.30, p=$ 0.03 , education, $\chi^{2}(10, N=176)=21.59, p=0.02$, marital status, $\chi^{2}(3, N=176)$ $=9.84, p=0.02$, and income of participants, $\chi^{2}(12, N=176)=26.88, p=0.01$.

\section{Results}

\subsection{Exploratory Factor Analysis}

Exploratory factor analysis (EFA) was used to analyze the OASUA using principal components extraction with varimax (orthogonal) rotation. On initial running, the variable of case management demonstrated no current or potential future participant use; therefore it was eliminated. With this variable removed, 37 -items were extracted meeting the criteria of an eigenvalue of 1.0 or greater, 
which accounted for $88.8 \%$ of the total variance. The first item loading accounted for $15.9 \%$ of the variance. All items factored into the theoretical components without significant cross loading. Results are shown in Table 1.

The scree test, factor eigenvalues, and amount of variance accounted for yielded four factors, which were all greater than 0.40 . Sixty items loaded onto factor one. Most of the 60 items, with the exception of current health insurance use, related to services participants' felt would be used in the future or were items of future perceived need. Ten items loaded onto the second factor. These items were related to participants' current use and service satisfaction in the areas of service referral (i.e., adult protection services, consumer affairs and legal counsel, counseling and support groups, information and referral, elder abuse consultation) and need for durable medical equipment. The third factor loaded 10 items. Items centered on current and future older adult activities (i.e., senior center activities, religious programs, senior meal sites); as well as, the perceived need for information on grandparents raising grandchildren. Older adult activities and program availability may have relevant connections for those interviewed. Eleven items loaded onto the fourth factor. These items were health related (i.e., health insurance satisfaction and perceived future need; current use, satisfaction with, and perceived future need for hearing and vision clinics; current home health care use; current use and satisfaction with respite care; and current and future use of veteran services) or dealt with future use of senior low rent housing/non-subsidized. Senior low rent housing may be part of this last factor with the recognition that as overall health declines financial consequences follow. A decline in finances directly impact type and quality of housing.

\subsection{Reliability of the OASUA}

Cronbach's $\alpha$ was used to assess the internal consistency of responses within the OASUA. The scale demonstrated overall excellent reliability (Cronbach's $\alpha=$ 0.95 ), with subscale reliabilities ranging from 0.76 to 0.94 (current services used: 0.76 ; service satisfaction: 0.77 ; future service utilization: 0.92 ; future perceived service needs: 0.94 ).

\subsection{Validity of the OASUA}

The convergent validity of OASUA was examined by considering the relationship between the subscales. The rationale being that current or recent service use would predict future service use and perceived needs, as well as satisfaction with services experienced. Using a Pearson's Product-Moment Correlation, the total number of current services used correlated with total perceived future service use, $r(173)=0.59, p<0.001$, and with total number of future perceived service needs $r(174)=0.43, p<0.001)$. A correlation was evident between future service utilization and future perceived needs $r(173)=0.84, p<0.001)$. Discriminant validity was apparent with the total number of services used not being related to total reported service satisfaction $r(166)=-0.03, p>0.05)$. The number of the services used was correlated with increases in future use and perceived need. 
Table 1. Factor loadings for exploratory factor analysis with varimax rotation of OASUA.

\begin{tabular}{|c|c|c|c|c|}
\hline Item & Factor 1 & Factor 2 & Factor 3 & Factor 4 \\
\hline Health, Education and Wellness (AAA, Wellness Line) (F) & 0.698 & & & \\
\hline Housing (Assisted Living) (F) & 0.687 & & & \\
\hline Caregiver Program (e.g., Alzheimer's Association) (F) & 0.686 & & & \\
\hline Home Health Care (F) & 0.678 & & & \\
\hline Information and Referral (F) & 0.675 & & & \\
\hline Caregiver Program (e.g., Alzheimer’s Association) (PN) & 0.659 & & & \\
\hline Hospice \& Palliative Services (F) & 0.654 & & & \\
\hline Nursing Home (PN) & 0.647 & & & \\
\hline Transportation $(\mathrm{F})$ & 0.634 & & & \\
\hline Elder Abuse (F) & 0.630 & & & \\
\hline Outpatient Physical \& Occupational Therapy (F) & 0.619 & & & \\
\hline Adult Day Care (PN) & 0.614 & & & \\
\hline Adult Day Care (F) & 0.611 & & & \\
\hline Respite Care (F) & 0.605 & & & -0.491 \\
\hline Physician (F) & 0.602 & & & \\
\hline Outpatient Physical \& Occupational Therapy (PN) & 0.601 & & & \\
\hline Options for Long-term Care (F) & 0.591 & & & \\
\hline Financial Assistance $(\mathrm{F})$ & 0.590 & & & \\
\hline Chore Service Program (F) & 0.589 & & & \\
\hline Personal Alert System (F) & 0.586 & & & \\
\hline Hearing \& Vision Clinics (F) & 0.581 & & & \\
\hline Home Health Care (PN) & 0.580 & & & \\
\hline Housing (Assisted Living) (PN) & 0.580 & & & \\
\hline Nursing Home (F) & 0.576 & & & \\
\hline Counseling \& Support Groups (PN) & 0.575 & & & \\
\hline Information (PN) & 0.575 & & & \\
\hline Energy Assistance (F) & 0.573 & & & \\
\hline Options for Long-term Care (PN) & 0.569 & & & \\
\hline Hospital (F) & 0.568 & & & \\
\hline Elder Abuse (PN) & 0.562 & & -0.424 & \\
\hline Health, Education and Wellness (AAA, Wellness Line) (PN) & 0.561 & & & \\
\hline Consumer Affairs (PN) & 0.561 & 0.417 & & \\
\hline Food (Food stamps, Grocery Shopping \& Delivery) (F) & 0.561 & & & \\
\hline Durable Medical Equipment (PN) & 0.561 & & & \\
\hline Hospice \& Palliative Services (PN) & 0.558 & & & \\
\hline Counseling \& Support Groups (F) & 0.556 & 0.495 & & \\
\hline Chore Service Program (PN) & 0.554 & & & \\
\hline Health Insurance (Benefits Counseling, Medicaid, Medicare) (F) & 0.548 & & & \\
\hline Senior Nutrition Program (Meals on Wheels, Food Bank) (F) & 0.530 & & & \\
\hline Transportation (PN) & 0.530 & & & \\
\hline Ombudsman (PN) & 0.528 & & & \\
\hline Emergency Room (F) & 0.527 & & & \\
\hline Hospital (PN) & 0.526 & & & \\
\hline Senior Nutrition Program (Meals on Wheels, Food Bank) (PN) & 0.516 & & & \\
\hline
\end{tabular}




\begin{tabular}{|c|c|c|c|c|}
\hline Housing Subsidized (PN) & 0.511 & & & \\
\hline Ombudsman (F) & 0.511 & & & \\
\hline Durable Medical Equipment (F) & 0.505 & & & \\
\hline Legal Assistance (F) & 0.503 & & & \\
\hline Physician (PN) & 0.492 & & & \\
\hline Housing Subsidized (F) & 0.476 & & & -0.420 \\
\hline Recreation Center (PN) & 0.469 & & & \\
\hline Personal Alert System (PN) & 0.468 & & & \\
\hline Respite Care (PN) & 0.464 & & & \\
\hline Adult Protective Services (F) & 0.445 & & & \\
\hline Health Insurance (Benefits Counseling, Medicaid, Medicare) (U) & 0.437 & & & \\
\hline Employment Services (PN) & 0.431 & & & \\
\hline Financial Assistance (PN) & 0.425 & & & \\
\hline Energy Assistance (PN) & 0.418 & & & \\
\hline Adult Protective Services (PN) & 0.405 & & & \\
\hline Elder Abuse (U) & & 0.820 & & \\
\hline Consumer Affairs (U) & & 0.820 & & \\
\hline Adult Protective Services (U) & & 0.816 & & \\
\hline Consumer Affairs (S) & 0.424 & 0.810 & & \\
\hline Counseling \& Support Groups (U) & & 0.810 & & \\
\hline Adult Protective Services (S) & 0.431 & 0.784 & & \\
\hline Consumer Affairs (F) & 0.491 & 0.618 & & \\
\hline Information (U) & 0.484 & & & \\
\hline Information (S) & 0.418 & & & \\
\hline Durable Medical Equipment (S) & 0.417 & & & \\
\hline Senior Centers ( $\mathrm{S}$ ) & & & 0.610 & \\
\hline Senior Meal Site Locations/Specific to Seniors (S) & & & 0.603 & \\
\hline Senior Centers (U) & & & 0.602 & \\
\hline Senior Centers $(F)$ & & & 0.583 & \\
\hline Senior Meal Site Locations/Specific to Seniors (U) & & & 0.561 & \\
\hline Senior Centers (PN) & & & 0.468 & \\
\hline Senior Meal Site Locations/Specific to Seniors (F) & & & 0.458 & \\
\hline Grandparents Raising Grandchildren (PN) & & & -0.488 & \\
\hline Religious Programs (U) & & & 0.431 & \\
\hline Religious Programs (F) & & & 0.426 & \\
\hline Veteran Services (U) & & & & -0.606 \\
\hline Veteran Services (F) & 0.420 & & & -0.574 \\
\hline Respite Care (U) & 0.412 & & & -0.549 \\
\hline Respite Care (S) & 0.431 & & & -0.501 \\
\hline Health Insurance (Benefits Counseling, Medicaid/Medicare) (PN) & 0.401 & & & 0.483 \\
\hline Hearing \& Vision Clinic (PN) & 0.477 & & & 0.481 \\
\hline Health Insurance (Benefits Counseling, Medicaid, Medicare) (S) & & & & 0.461 \\
\hline Health \& Vision Clinic (U) & & & & 0.458 \\
\hline Housing Seniors Only, Non-subsidized/Low-Rent (F) & 0.402 & & & -0.442 \\
\hline Home Health Care (U) & 0.412 & & & -0.435 \\
\hline Health \& Vision Clinic (S) & & & & 0.426 \\
\hline
\end{tabular}

Note: $\mathrm{F}=$ Future Use; $\mathrm{PN}=$ Perceived Need in Future; $\mathrm{S}=$ Satisfaction; $\mathrm{U}=$ Current or Recent Use. 
Service satisfaction did not correlate with future service utilization $r(165)=$ $-0.14, p>0.05$, but was negatively correlated with future perceived needs $r(173)$ $=-0.20, p<0.01)$. This finding suggests lower current satisfaction with service use has the potential to be related to higher future perceived service needs.

\section{Discussion}

This study was intended to develop and examine the psychometric properties of the OASUA with an older adult population. The EFA indicated a four-factor solution. The OASUA is an 86-item instrument designed to measure current service use and satisfaction (43-items), as well as future service use and potential service needs (43-items) supporting older adults. The OASUA provides an indication of awareness on service availability along with frequency of use. Case management as a variable choice was eliminated from the OASUA for two reasons: no participant indicated use of this service, which was removed from the EFA and following an ensuring review case management was not listed as one of the 19 services indicated in a national survey for HCBS availability [10]. These same researchers listed tax preparation assistance in the list of 19 services and as a result this variable was added to the OASUA keeping it an 86-item measure for future investigation. Table 2 provides a subsequent revision of the OASUA.

Findings from this study give support for the need component of the Social Behavior Model and recognition for older adults' informed choices in service awareness and potential utilization as mandated by the Older Americans Act Reauthorization of 2016

(https://www.congress.gov/bill/114th-congress/senate-bill/192). One method to promote informed choice is the measurement of HCBS service availability and use by individuals programs are intended to serve. Measurement of the older adult's aging experience as tied to service utilization and frequency of use, along with a needs assessment is of particular importance in rural settings. The limited availability and access found in rural areas is recognized as some of the most significant barriers to the use of services and long-term care [7]. The OASUA can be used as a single point of measure or to evaluate changes in community-based service use, satisfaction, future service use, and/or perceived needs over time. Older adults should be recognized as the consumers they are and who have the ability to evaluate community-based services.

\section{Limitations and Conclusion}

The intent of this research was to develop a service needs assessment. Several limitations exist: 1) the current study included a predominantly Caucasian rural sample; 2) participants for this study resided in two different states; however, the service offerings were similar in number and structure allowing for thoughtful comparison; 3) all collected data was self-report and interpreted as such; 4) convenience sampling was used to identify the population of interest. The sampling method employed was chosen because HCBS person level data was only available to employees of the AAA. A random sample was approached by randomly 
Table 2. Older adult service usage assessment.

\section{(Previous/Current Perceived Needs)}

Which of the following programs are you currently using or have used. Please indicate the frequency of your use of a program (0: not used; 1: single use; 2: multiple uses but not weekly; 3: weekly; 4: twice a week; 5 : more than twice a week) and your satisfaction with the program (0: not satisfied; 1 : limited satisfaction; 2 : some satisfaction; 3 : moderately satisfied; 4: very satisfied; 5: extremely satisfied). If a program has not been used then a satisfaction score is not required.

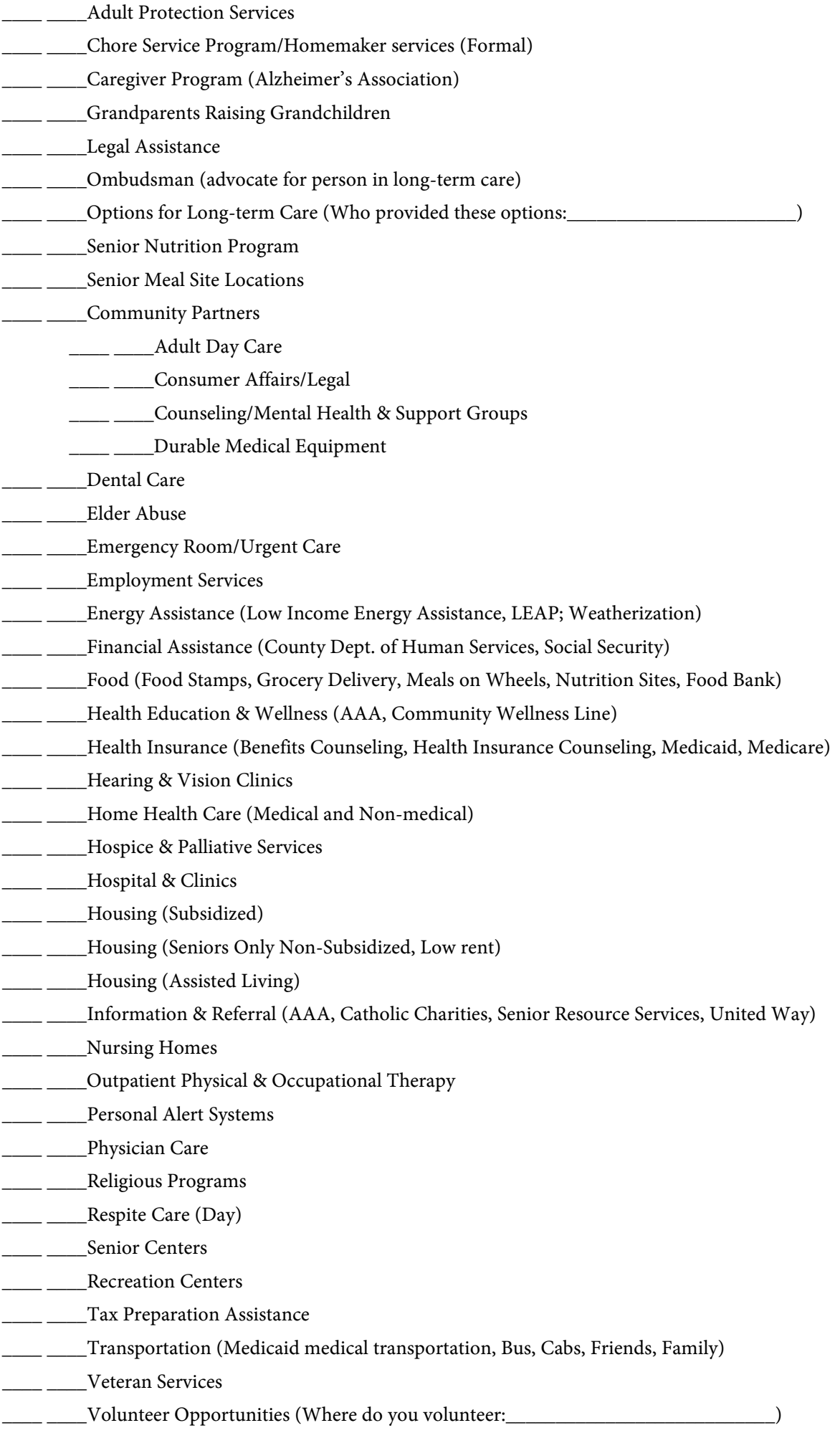




\section{Continued}

\section{(Future Perceived \& Expressed Needs)}

Which of the following programs are you interested in using in the future. Please indicate the frequency of possible use ( 0 : no use; 1 : single use; 2 : multiple uses by not weekly; 3 : weekly; 4 : twice a week; 5 : more than twice a week) and perceived need of the program (0: not needed; 1 : limited need; 2 : some need; 3: moderate need; 4 : very needed; 5: extremely needed).

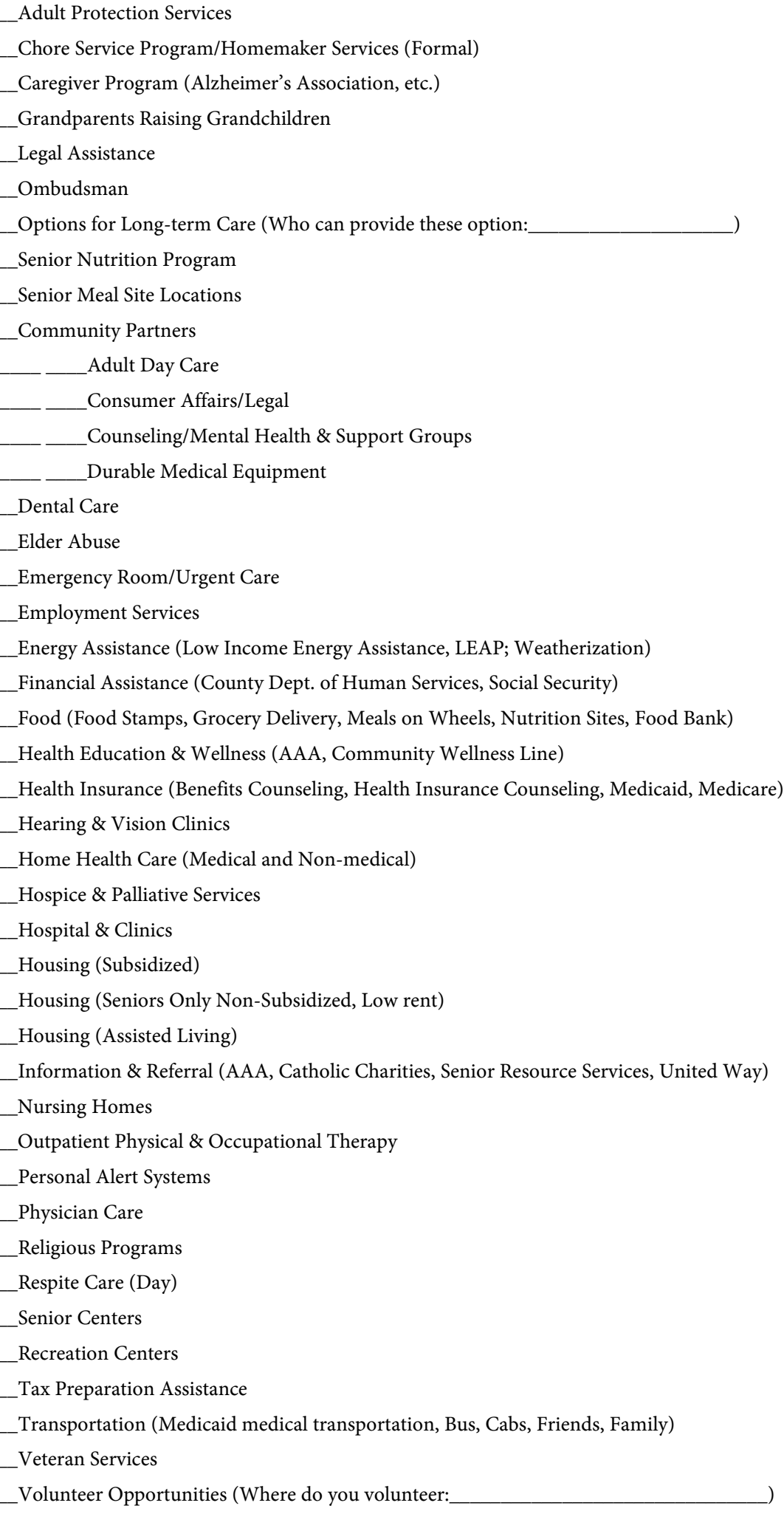


sampling facilities where older adults congregate to create a sampling frame of places. From the randomly selected settings list, individuals were sampled-as they self-selected whether to participate; and 5) measurement of service use via survey method is less reliable when a single assessment is obtained. Multiple measurement points would allow for increased accuracy and the examination of linear relationships. As a result of these limitations, further data collection should occur within other states and with more diverse sampling. Despite these limitations, the OASUA is an instrument that could be administered multiple times throughout a calendar year to improve participant recall and provide for a more complete picture of service use and allowing for measurement of predictive validity. With multiple measurements, changes in perceptions can be identified.

In conclusion, OASUA can be used to gauge current service use and frequency, overall satisfaction with services; as well as perceptions of future service use and frequency, and potential need for services in the future. The OASUA may help to inform stakeholders and potential insurers on the service needs in these two states along with other rural areas. This measure may provide community-based service providers with an increased awareness of region specific current and future service use and needs for rural older adults and the associated satisfaction. As the population continues to age, bettering HCBS use through effective communication of service availability may improve the overall aging experience. Sustained measurement of service use and perceived needs could play a role toward furthering healthy aging and informing funding policy with regard to service cost effectiveness. Future research may want to ascertain additional information regarding service use management strategies (e.g., telemedicine, family and extended support) and additional community-based services (e.g., tax preparation assistance, etc.) thereby allowing for an adjustment to ineffective individual approaches. Findings from the current study may not be generalizable to all rural areas; however, understandings gained may be transferable to regions with similar services and circumstances.

\section{Funding}

Publication of this article was funded in part by the University of Northern Colorado Fund for Faculty Publication.

\section{References}

[1] Coburn, A.F., Griffin, E., Thayer, D., Croll, Z. and Ziller, E.C. (2016) Are Rural Older Adults Benefiting from Increased State Spending on Medicaid Home and Community-Based Services? Maine Rural Health Research Center: Research \& Policy Brief, PB-65. 1-10.

[2] Medicaid (2016) Home \& Community-Based Services 1915 ○. https://www.medicaid.gov/medicaid/hcbs/authorities/1915-c/index.html

[3] Borders, T.F., Aday, L.A. and Xu, K.T. (2004) Factors Associated with HealthRelated Quality of Life Among An Older Population in a Largely Rural Western Region. The Journal of Rural Health, 20, 67-75. https://doi.org/10.1111/j.1748-0361.2004.tb00009.x 
[4] Bull, C.N., Krout, J.A., Rathbone-McCuan, E. and Shreffler, M.J. (2001) Access and Issues of Equity in Remote/Rural Areas. The Journal of Rural Health, 17, 356-359. https://doi.org/10.1111/j.1748-0361.2001.tb00288.x

[5] Li, H., Kyrouac, G.A., McManus, D.Q., Cranston, R.E. and Hughes, S. (2012) Unmet Home Care Service Needs of Rural Older Adults with Alzheimer's Disease: A Perspective of Informal Caregivers. Journal of Gerontological Social Work, 55, 409425. https://doi.org/10.1080/01634372.2011.650318

[6] Baernholdt, M., Yan, G., Hinton, I., Rose, K. and Mattos, M. (2012) Quality of Life in Rural and Urban Adults 65 Years and Older: Findings from the National Health and Nutrition Examination Survey. Journal of Rural Health, 28, 339-347. https://doi.org/10.1111/j.1748-0361.2011.00403.x

[7] Coburn, A.F. and Bolda, E.J. (2001) Rural Elders and Long-Term Care. Western Journal of Medicine, 174, 209-213. https://doi.org/10.1136/ewjm.174.3.209

[8] Krout, J.A. (2001) Community Services and Housing for Rural Elders. Public Policy \& Aging Report, 12, 6-8. https://doi.org/10.1093/ppar/12.1.6

[9] US Department of Health \& Human Services (2016) Getting Care Where I'm Most Comfortable-At Home.

http://www.hhs.gov/blog/2016/03/11/getting-care-where-i-m-most-comfortable-ho me.html

[10] Sonnega, A., Robinson, K. and Levy, H. (2016) Home and Community-Based Service and Other Senior Service Use: Prevalence and Characteristics in a National Sample. Home Health Care Services Quarterly, 36, 16-28. http://dx.doi.org/10.1080/01621424.2016.1268552

[11] Li, H. (2006) Rural Older Adults' Access Barriers to In-Home and CommunityBased Services. Social Work Research, 30, 109-118. https://doi.org/10.1093/swr/30.2.109

[12] Whiteneck, G.G., Harrison-Felix, C.L., Mellick, D.C., Brooks, C.A., Charlifue, S.B. and Gerhart, L.A. (2004) Quantifying Environmental Factors: A Measure of Physical, Attitudinal, Service, Productivity, and Policy Barriers. Rehabilitation, 85, 1324 1335.

[13] Geron, S.M., Smith, K., Tennstedt, S., Jette, A., Chassler, D. and Kasten, L. (2000) The Home Care Satisfaction Measure: A Client-Centered Approach to Assessing the Satisfaction of Frail Older Adults With Home Care Services. Journal of Gerontology B: Psychological Sciences and Social Sciences, 55, S259-S270. https://doi.org/10.1093/geronb/55.5.S259

[14] Wacker, R.R. and Roberto, R.A. (2014) Community Resources for Older Adults: Programs and Services in an Era of Change. SAGE Publishing, Los Angeles.

[15] Andersen, R. (1995) Revisiting the Behavioral Model and Access to Medical Care: Does It Matter? Journal of Health and Social Behavior, 36, 1-10. https://doi.org/10.2307/2137284

[16] U.S. Department of Health \& Human Services (2016) Administration on Aging (AoA) Older Americans Act Reauthorization Act of 2016. https://aoa/acl/gov/AoA_Programs/OAA/Reauthorization/2016/Index.aspx

[17] Colorado Rural Health Center (2014) Snapshot of Rural Health in Colorado. http://coruralhealth.org/wp-content/uploads/2014/09/2014.RuralHealth.Snapshot.p df

[18] Russ, R. and Speck, A.M. (2009) The New "Frontier": Older Adults in Nebraska Rural Senior Centers. Journal of Rural Community Psychology, E12, 1-7.

[19] Rural Health Information Hub (2016) Am I Rural? https://www.ruralhealthinfo.org/am-i-rural/report?lat=40.72469\&lng=-103.11011 
Submit or recommend next manuscript to SCIRP and we will provide best service for you:

Accepting pre-submission inquiries through Email, Facebook, LinkedIn, Twitter, etc. A wide selection of journals (inclusive of 9 subjects, more than 200 journals)

Providing 24-hour high-quality service

User-friendly online submission system

Fair and swift peer-review system

Efficient typesetting and proofreading procedure

Display of the result of downloads and visits, as well as the number of cited articles Maximum dissemination of your research work

Submit your manuscript at: http://papersubmission.scirp.org/

Or contact aar@scirp.org 